\title{
Jackhammer Esophagus Accompanied by Esophageal Intramural Pseudodiverticulosis
}

\author{
Kazuya Takahashi, Satoshi Ikarashi, Junji Yokoyama and Shuji Terai
}

Key words: high resolution manometry, jackhammer esophagus, esophageal intramural pseudodiverticulosis

(Intern Med 57: 1051-1052, 2018)

(DOI: 10.2169/internalmedicine.9734-17)

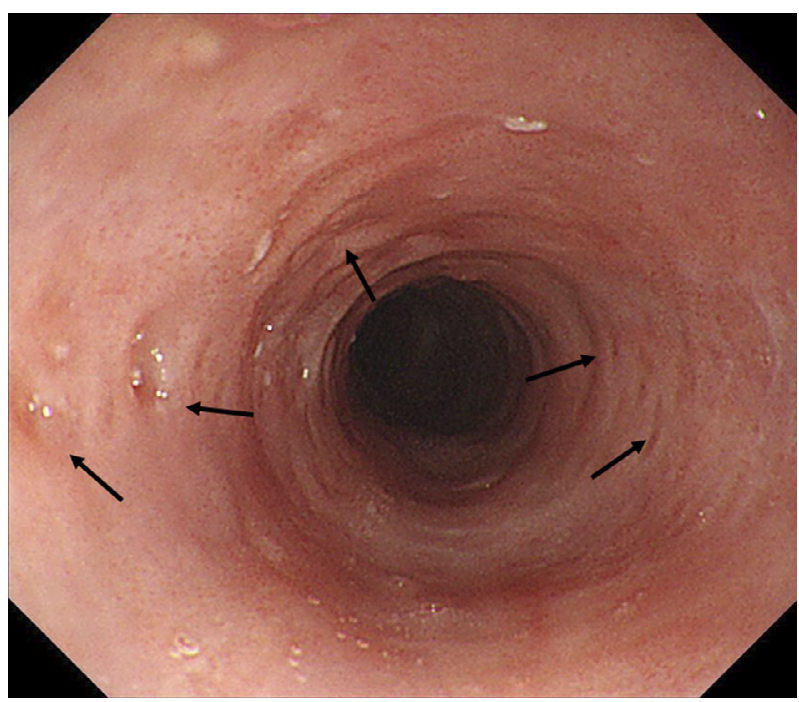

Picture 1.

A 60-year-old man presented with dysphagia. He consumed $40 \mathrm{~g}$ of alcohol and smoked 20 cigarettes per day. The patient had no history of diabetes mellitus, collagen disease, or candida esophagitis. Endoscopy revealed multiple small holes, a whitish mucosa, and a relatively narrow lumen (Picture 1, black arrow). Esophagography with barium swallow revealed multiple flask-shaped projections throughout the cervical and upper thoracic esophagus (Picture 2). We therefore diagnosed the patient with esophageal intramural pseudodiverticulosis (EIPD). Because it has been reported to be related to esophageal functional disorders, such as achalasia or nutcracker esophagus, we performed high resolution manometry $(\mathrm{HRM})(1,2)$. HRM revealed extremely strong contractions of the esophageal body and normal lower esophageal sphincter relaxation. The distal contractile integral was $16,750.9 \mathrm{mmHg} \cdot \mathrm{s} \cdot \mathrm{cm}$ (normal range <

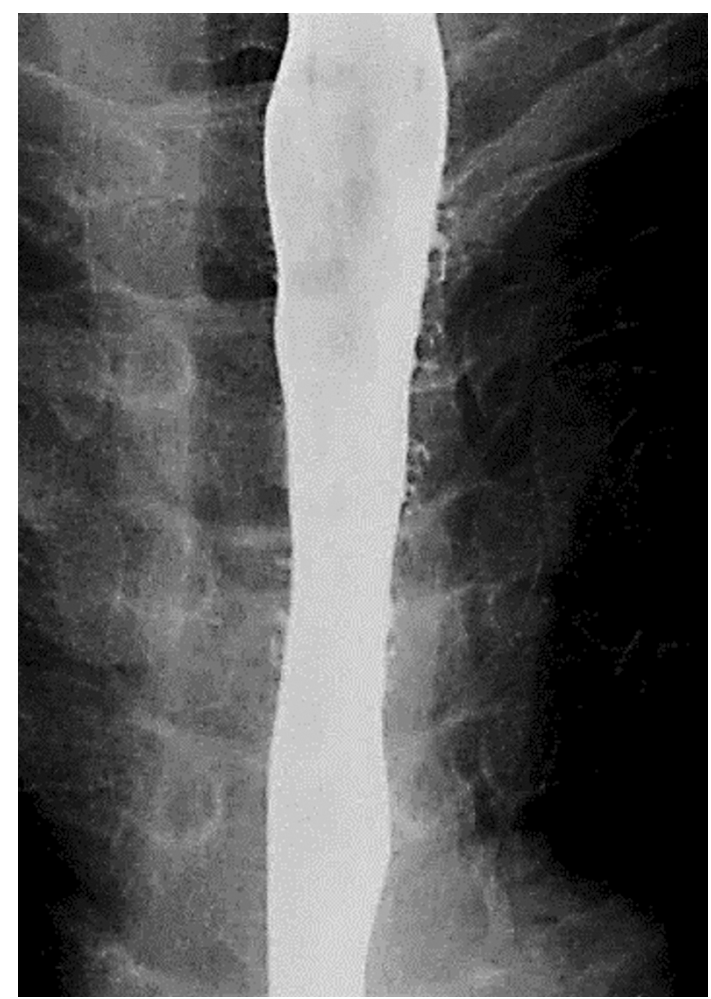

Picture 2.

$8,000 \mathrm{mmHg} \cdot \mathrm{s} \cdot \mathrm{cm}$ ) (Picture 3). The patient met the criteria for jackhammer esophagus and was diagnosed with jackhammer esophagus accompanied by EIPD. We hypothesized that extremely high pressure in the esophagus caused EIPD. The previous studies were performed by conventional manometry; thus, this is the first report to investigate the esophageal function of a patient with EIPD using HRM.

The authors state that they have no Conflict of Interest (COI).

Division of Gastroenterology and Hepatology, Graduate School of Medical and Dental Sciences, Niigata University, Japan Received: June 28, 2017; Accepted: July 22, 2017; Advance Publication by J-STAGE: December 8, 2017 Correspondence to Dr. Kazuya Takahashi, kazuya911@med.niigata-u.ac.jp 


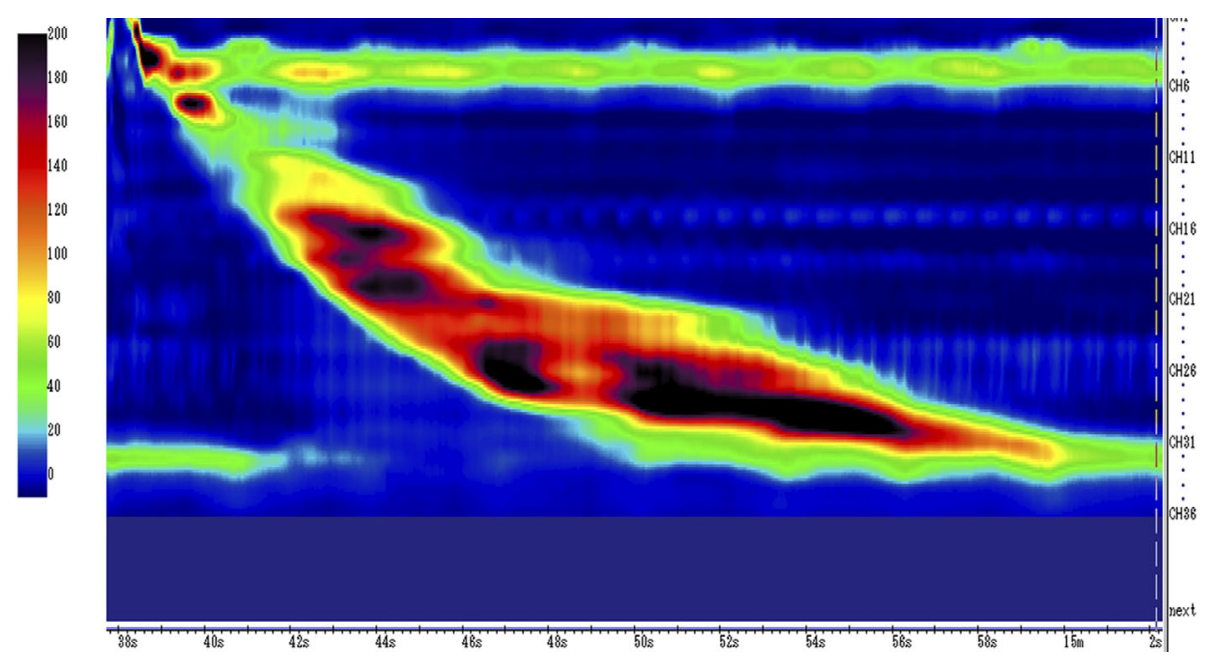

Picture 3.

\section{References}

1. Ritz J, Germer C, Zimmer T, et al. Esophageal hypermotility associated with intramural pseudodiverticulosis. Primary esophageal disease or epiphenomena? Surg Endosc 14: 681, 2000.

2. Turan I, Ozen E, Bor S, et al. Esophageal intramural pseudodiver- ticulosis associated with achalasia: an unusual endoscopic appearance. Endoscopy 41 (Suppl 2): E23-E24, 2009.

The Internal Medicine is an Open Access article distributed under the Creative Commons Attribution-NonCommercial-NoDerivatives 4.0 International License. To view the details of this license, please visit (https://creativecommons.org/licenses/ by-nc-nd/4.0/).

(C) 2018 The Japanese Society of Internal Medicine Intern Med 57: 1051-1052, 2018 